\title{
Student Paramedic Attitudes Towards the Elderly: A cross- sectional study
}

\author{
Linda Ross MHIthProfEd, Tom Duigan BOutdoorEd, Malcolm Boyle PhD, Brett Williams PhD \\ Affiliation: \\ Department of Community Emergency Health and Paramedic Practice, Monash University, Victoria, Australia
}

\begin{abstract}
Introduction

It is well known that Australia has an aging population and that the elderly are disproportionately overrepresented in the patients seen by ambulance paramedics. While research to date has primarily focussed on the attitudes towards the elderly held by nursing and medical students, there is a current paucity of research about the perspective of paramedic students. The objective of this study was to identify the attitudes of paramedic students from a large Australian university towards the elderly.
\end{abstract}

\section{Methods}

In 2013, second year paramedic students from Monash University, Melbourne, Australia were invited to participate in this cross-sectional study and record their attitudes towards the elderly (age >65) using the Aging Semantic Differential (ASD) questionnaire. The ASD utilises a 7 point bipolar Likert scale questionnaire consisting of 32 items and three subscales: Instrument-Ineffective; AutonomousDependent; Personal Acceptability-Unacceptability.

\section{Results}

Fifty six second year paramedic students participated in the study. The participants were predominantly $<26$ years of age $n=48(85.7 \%)$ and female $n=36(64.3 \%)$. Subscale results produced the following mean scores: Instrument-Ineffective (mean=35.05, SD=5.01); Autonomous-Dependent (mean=34.25, SD=4.26); Personal Acceptability_Unacceptability (mean=49.47, SD=6.44).

\section{Conclusion}

These results suggest that while student paramedics possess a healthy respect for the elderly, they also harbour some preconceived negative ideas about them. Ultimately, these attitudes may impact on a paramedic's interaction with, and management of the elderly patient, which raises questions about whether students are being adequately prepared for clinical practice.

\section{Keywords}

Attitudes, elderly, paramedic, patient care

\section{INTRODUCTION}

It is widely accepted that Australia, along with the rest of the developed world, has an aging population and that the elderly are disproportionately overrepresented in emergency healthcare (1-3). Increasing life expectancies, declining fertility rates and advances in medicine are often cited as responsible for this aging trend and the associated rise in the demand for emergency ambulance services (4-6).

Today's elderly (age >65 years) currently comprise about $14 \%$ of Australia's total population, but latest projections estimate this 
figure will nearly double to $25 \%$ over the next 25 years $(4,7)$. Around the world advancing age has led to increased ambulance demand and the use of these services amongst the elderly is expected to continue to rise (8-10). Patients aged over 85 years of age are eight times more likely to utilise ambulance services than those aged $45-60$ years, indicating an exponential pattern of growth (4). Such statistics highlight the need for future paramedics to be well trained and prepared to care for elderly patients.

Elderly patients have complex and diverse needs and are often prone to the cumulative effects of multiple chronic diseases and disability $(8,10$, 11). Some of the challenges associated with care of the elderly include altered mentation, atypical presentation of diseases, complex pharmacological interactions and the increased likelihood of co-morbidities (12). Specific communication barriers may lead to the inability or failure of patients to report their symptoms and to provide accurate, consistent medical history (12). Ultimately, this can make prehospital assessment difficult and frustrating and thus influence attitudes of healthcare providers (5). As such paramedics need to be able to adapt their practice to meet the physical, social, psychological, cognitive and emotional challenges associated with these patients.

Reports across healthcare, particularly nursing and medicine, have documented widespread negative attitudes held by healthcare professionals towards the elderly $(2,5,6,13-16)$. Studies on the attitudes of healthcare professionals in hospital environments have indicated that some regard the elderly as unexciting, depressing, frustrating, boring, are more strenuous to manage and require less technical skill $(5,8,11,13,17)$. Similarly studies of medicine, nursing and social work students have also reported some negative and stereotypical attitudes $(13,18,19)$. While these attitudes have been uncovered amongst other professions, it is unclear if these attitudes exist amongst paramedics. There is very little current research on the quality of care for elderly patients in the prehospital setting in Australia $(8,9)$, nor is there any peer-reviewed literature on student paramedic attitudes towards the elderly. What is known however, is that negative perceptions are amplified due to the distorted interactions with the chronically sick patients seen in emergency healthcare (16). Another factor identified in the overrepresentation of ambulance use by the elderly is the high prevalence of social and care related problems due to declining mobility, selfcare or isolation (10).

Negative or ageist attitudes have the potential to adversely affect the quality of care provided $(1,2$,
$6,13,16,18,20-23)$. Ageism is defined as the systematic stereotyping of, and discrimination against people, because they are old $(5,16,24)$. It often leads individuals to view older adults as unproductive, depressing, sickly, and to believe that cognitive impairment is normative by reinforcing stereotypical beliefs (25). This then legitimises the use of a patients age to systematically categorise them and therefore, make biased or discriminative decisions about what resources and opportunities are made available or denied $(16,25)$. These judgments therefore affect overall patient assessment, the quality of treatment provided, resources allocated and overall patient outcomes $(13,15,17)$. Current research suggests that improving attitudes is the cornerstone to improving care as attitudes influence how information is interpreted, how knowledge is acquired, and ultimately lead to changes in behaviour and practice $(11,15,20)$.

It is currently unclear how much time and content is provided in paramedic curricula in Australia on the complex biopsychosocial needs of the elderly. This raises the question as to whether students are being adequately prepared to manage elderly patients. Most of the research in related fields highlight the link between increased knowledge and education being influential components in shaping the development of desirable positive attitudes $(2,11,13,15,17,20,24,26)$. Current research also indicates that students who receive special education and training in elderly patient management are able to build their knowledge base and understanding to ultimately improve their level of care $(2,11,27)$. Exposure to positive professional role models has also been identified as a significant influence on new graduate attitudes towards patients $(13,17)$. Further research examining the link between training and attitudes towards the elderly is important as healthcare students often form unfavourable attitudes and ageist beliefs during their education and this therefore represents an opportune time to have the greatest influence (5).

The objective of this study was to identify the attitudes of paramedic students from a large Australian university towards the elderly.

\section{METHODS}

\section{Study Design}

This was a cross-sectional study using a paperbased survey to elicit responses from student paramedics about their attitudes towards the elderly.

\section{Participants}

A convenience sampling method was used to recruit students enrolled in second year of the 
Bachelor of Emergency Health (Paramedic) at Monash University in first semester 2013. Second year students were chosen for this study due to their limited exposure to patients through clinical placement at this point of the course as opposed to third years who had already participated in extensive placements which could have impacted on their attitudes. First year students were in the process of undertaking clinical placements and we did not want their exposure in the clinical placement to potentially bias their view, therefore they were not considered for inclusion.

There were 117 second year students eligible to participate in the study however only those in attendance on the day the survey was distributed were invited to participate.

\section{Instrumentation}

To examine the self-reported attitudes toward the elderly the Aging Semantic Differential (ASD) questionnaire was used. The ASD was developed by Rosencranz and McNevin in 1969 (28) and has been widely used throughout the literature in measuring attitudes of nursing and medical students towards the elderly and to measure agebased discrimination $(13,18,22,29)$. The ASD utilises a 7 point bipolar Likert scale questionnaire that consists of 32 items and three dimensions. The "Instrument-Ineffective" dimension includes items such as progressive vs old fashioned and strong vs weak. A low score in this dimension suggests an individual capable of pursuing goals and adapting to change (27). The "AutonomousDependent" dimension includes items such as independent vs dependent and decisive vs indecisive. A low score in this dimension indicates a person contributes as much to society as he/she derives from it (27). The "Personal AcceptabilityUnacceptability" includes items such as flexible vs inflexible and tolerant vs intolerant and relates to an individual's ability to foster and maintain social interactions (27). Respondents circle a number along the bipolar Likert scale from 1 (positive adjective) to 7 (negative adjective) that best suited their perceptions of the elderly.

There is currently no accepted 'gold standard' for measuring or identifying attitudes as many of the existing tools have various limitations (1). The tools and scales used to measure and collate the data are also described by some as old fashioned and inadequate with some studies doubting the accuracy of the ASD, thereby regarding it as outdated and tailored to an old fashioned generation based upon male perceptions (30). There are also questions surrounding its psychometric properties (20). A refined version has been proposed but has been used with limited success as it lacks the depth in dimensions that the original version holds $(18,30)$. As such, the original ASD scale offers the most rounded assessment criteria and was chosen as the primary measure for this study.

\section{Procedure}

At the completion of a lecture on an unrelated topic, students in attendance were invited to participate in the study (approximately 60 students). They were provided with an explanatory statement and were informed that participation in the study was voluntary, anonymous and that they could withdraw at any time prior to submitting the questionnaire. A nonteaching member of staff facilitated the process and participants were administered a questionnaire containing the ASD and a brief set of demographic questions. Consent for participation in the study was implied by completing and submitting the questionnaire.

\section{Data Analysis}

The SPSS program (Statistical Package for the Social Sciences, Version 20.0.0, IBM Corporation, Armonk, New York, U.S.A.) was used for data storage, tabulation and analysis. Descriptive statistics, means and standard deviation (SD) were used to describe the demographic and ASD data.

\section{Ethics}

Ethics approval for the study was granted by the Monash University Human Research Ethics Committee.

\section{RESULTS}

\section{Participant Demographics}

There were 56 (48\%) eligible students who participated in the study. The participants were predominantly $<26$ years of age $n=48(85.7 \%)$ and female $n=36(64.3 \%)$.

\section{Subscale Results}

Subscale results produced the following mean scores: Instrument-Ineffective (mean $=35.05$, $\mathrm{SD}=5.01$ ); Autonomous-Dependent (mean=34.25, SD=4.26); Personal AcceptabilityUnacceptability (mean $=49.47, \mathrm{SD}=6.44)$, see Table 1.

\section{Item-level Results}

At an item-level, the most negative attitudes were found within the Instrument - Ineffective sub-scale. This sub-scale recorded an overall mean of 4.21 and also recorded the most negative result on the Progressive- Old-fashioned item, scoring a mean of 4.77 , and SD 1.03. Students also recorded a notable negative response on the FlexibleInflexible item with a mean of 4.48, and SD 1.75. Full distribution of item-level results can be seen in Table 2. 


\begin{tabular}{lccccc}
$\begin{array}{l}\text { Aging Semantic } \\
\text { Differential (ASD) } \\
\text { Subscale Domains }\end{array}$ & $\begin{array}{l}\text { No. of } \\
\text { Items per } \\
\text { Subscale }\end{array}$ & $\begin{array}{l}\text { Min. } \\
\text { Possible } \\
\text { Domain } \\
\text { Score }\end{array}$ & $\begin{array}{l}\text { Max. } \\
\text { Possible } \\
\text { Domain } \\
\text { Score }\end{array}$ & Mean (M) & $\begin{array}{l}\text { Standard } \\
\text { Deviation } \\
\text { (SD) }\end{array}$ \\
\hline $\begin{array}{l}\text { Instrument-Ineffective } \\
\text { Autonomous- }\end{array}$ & 9 & 9 & 63 & 35.05 & 5.01 \\
$\begin{array}{l}\text { Dependent } \\
\begin{array}{l}\text { Personal } \\
\text { Acceptability- }\end{array}\end{array}$ & 9 & 9 & 63 & 34.25 & 4.26 \\
$\quad$ Unacceptability & 14 & 14 & 98 & 49.47 & 6.44 \\
Table 1: Subscale results & & & & & \\
\hline
\end{tabular}

\begin{tabular}{|c|c|c|c|c|c|c|c|c|}
\hline $\begin{array}{l}\text { INSTRUMENT - } \\
\text { INEFFECTIVE }\end{array}$ & Mean & SD & $\begin{array}{l}\text { AUTONOMOUS } \\
\text { - DEPENDENT }\end{array}$ & Mean & SD & $\begin{array}{c}\text { PERSONAL } \\
\text { ACCEPTABILITY - } \\
\text { UNACCEPTABILITY }\end{array}$ & Mean & SD \\
\hline $\begin{array}{l}\text { Productive - } \\
\text { Unproductive }\end{array}$ & 3.91 & 1.13 & $\begin{array}{l}\text { Organised - } \\
\text { Disorganised }\end{array}$ & 3.18 & 1.16 & Friendly - Unfriendly & 2.53 & 0.92 \\
\hline Active - Passive & 3.95 & 1.03 & $\begin{array}{l}\text { Consistent - } \\
\text { Inconsistent }\end{array}$ & 3.27 & 1.15 & Trustful - Suspicious & 2.66 & 0.95 \\
\hline $\begin{array}{l}\text { Expectant - } \\
\text { Resigned }\end{array}$ & 4.04 & 0.81 & $\begin{array}{l}\text { Satisfied - } \\
\text { Dissatisfied }\end{array}$ & 3.48 & 0.97 & Pleasant - Unpleasant & 2.82 & 0.88 \\
\hline Strong - Weak & 4.13 & 1.05 & $\begin{array}{l}\text { Certain - } \\
\text { Uncertain }\end{array}$ & 3.84 & 1.14 & Neat - Untidy & 2.88 & 1.06 \\
\hline $\begin{array}{l}\text { Healthy - } \\
\text { Unhealthy }\end{array}$ & 4.23 & 1.03 & $\begin{array}{l}\text { Secure - } \\
\text { Insecure }\end{array}$ & 3.86 & 1.18 & Generous - Selfish & 2.9 & 1.31 \\
\hline Busy - Idle & 4.27 & 1.14 & $\begin{array}{l}\text { Self-Reliant - } \\
\text { Dependent }\end{array}$ & 3.86 & 1.05 & $\begin{array}{l}\text { Cooperative - } \\
\text { Uncooperative }\end{array}$ & 3.18 & 1.10 \\
\hline $\begin{array}{l}\text { Aggressive - } \\
\text { Defensive }\end{array}$ & 4.32 & 0.90 & $\begin{array}{l}\text { Independent - } \\
\text { Dependent }\end{array}$ & 3.95 & 1.09 & Happy - Sad & 3.32 & 1.01 \\
\hline $\begin{array}{l}\text { Liberal - } \\
\text { Conservative }\end{array}$ & 4.38 & 1.34 & $\begin{array}{l}\text { Decisive - } \\
\text { Indecisive }\end{array}$ & 3.96 & 0.76 & Hopeful - Dejected & 3.59 & 1.09 \\
\hline \multirow[t]{6}{*}{$\begin{array}{l}\text { Progressive - } \\
\text { Old fashioned }\end{array}$} & 4.77 & 1.03 & Rich - Poor & 4.00 & 0.87 & $\begin{array}{l}\text { Optimistic - } \\
\text { Pessimistic }\end{array}$ & 3.61 & 1.06 \\
\hline & & & & & & Exciting - Dull & 3.68 & 0.92 \\
\hline & & & & & & Handsome - Ugly & 3.7 & 0.91 \\
\hline & & & & & & Tolerant - Intolerant & 3.91 & 1.21 \\
\hline & & & & & & Ordinary - Eccentric & 3.98 & 1.05 \\
\hline & & & & & & Flexible - Inflexible & 4.48 & 1.18 \\
\hline
\end{tabular}

Table 2: Item level results 


\section{DISCUSSION}

This first of its kind study examining the attitudes of paramedic students towards the elderly is an important first step in the formation of an evidence base ultimately aimed at producing quality care for the elderly in the prehospital environment. Other health professions such as nursing, have not only found that negative attitudes towards the elderly exist but that these attitudes have a detrimental impact on patient care and outcomes $(13,15,17)$. The results from this study have highlight that some negative, and some positive preconceptions towards the elderly exist amongst this paramedic student cohort.

The Instrument - Ineffective sub-scale had the highest overall negative result and 7 out of the 9 items record a mean of greater than 4 (neutral point of the scale), indicating a more negative attitude. These findings suggest student paramedics regard the elderly as old fashioned, idle, conservative, unhealthy and defensive. A nursing study reported similar results using the ASD, with the Instrument - Ineffective dimension holding the most negative results (31). Similarly the Stewart et al study of 250 medical students produced remarkably similar results with the liberal-conservative and progressive-old fashioned items having the strongest negative deviation from the central point in this domain (18). It appears that these negative perceptions stem from the items related to declining level of functioning which often goes hand in hand with the aging process, and the belief that elderly people are fixed in their way of thinking. External factors such as media portrayal of the elderly, and clinical placement exposure to elderly patients with ailing health no doubt contribute to these preconceptions. Hawkins concluded that undergraduate health care students need to be presented with diverse cross-sections of elderly patients including those who are healthy in order to form balanced attitudes (18).

The results from the Autonomous - Dependent sub-scale were relatively neutral. Six individual items, independent - dependent, rich - poor, secure - insecure, self -reliant - dependent, certain - uncertain and decisive - indecisive were all within 0.16 of the neutral point on the scale. The remaining three items pointed towards the positive adjectives, consistent, satisfied and organised. These results indicate the students felt that elderly people have a good degree of selfreliance, certainty and autonomy. It is worth considering however, that the neutral effect could merely be the result of participants being unsure and selecting the midpoint of the scale as a 'don't know' option (18).
In the Personal Acceptability - Unacceptability sub-scale the results were the most positive overall. Very positive attitudes were present with respect to the traits of generosity, friendliness, tidiness and trust. Studies including acute care nurses and medical students also reported positive attitudes in relation to these traits $(18$, 32). Only one item, flexible - inflexible scored in the negative direction whilst others, tolerant intolerant and ordinary - eccentric were less than 0.09 on the positive side of neutral. The notion of inflexibility links back to the Instrument Ineffective sub-scale where results suggested students found the elderly old fashioned and conservative. Whilst some elderly people may have a degree of inflexibility the question is whether a paramedic holding that negative belief will be able to provide the best level of care. Perhaps the objective for educators is to provide undergraduates with knowledge and understanding about why elderly people may present as inflexible and how this can be overcome $(23,33)$.

\section{Future Research}

The results of this study indicate the need for future research in the area to not only determine the attitudes of paramedic students towards elderly patients, but also what influences these attitudes and how educators can best facilitate the formation of positive attitudes which will promote better patient care and health outcomes. Also worthy of further investigate is the impact knowledge and awareness of issues effecting the elderly has on attitudes and ultimate patient care. A longitudinal study examining the attitudes of paramedic undergraduates towards the elderly before, during and after exposure to various interventions including 'The Aging Game' (34) and community placements is planned.

\section{Limitations}

There are several limitations to this study including the small sample size from only one year level. In addition, this convenience sample of students generally had limited clinical experience (<20 hours of on-road ambulance placements). It was not known what, if any percentage of that time students spent managing elderly patients. It was also unknown what actual life experience, personal contact, or other professional, social or familial exposure students had with the elderly. Younger healthcare professionals ( $<25$ years of age) were shown in some studies to indicate more negative attitudes (17), and this may have skewed the data or added bias, given the majority of participants in this study were young ( $<26$ years of age). Additionally, the fact that it was a convenience sample implies potential selection bias, and perhaps was influenced by the type of students who volunteered to participate in the study. 


\section{CONCLUSION}

This study showed second year paramedic students hold a mixture of attitudes towards the elderly. Notably they regard the elderly as old fashioned and inflexible, yet consider them to be generous and friendly. Whilst these items were obviously positive or negative, many item results fell on, or deviated only slightly from, the neutral midpoint of the scale indicating an undecided or uninformed view of the elderly. Better tailored programs for student paramedics that foster knowledge and understanding of the elderly will promote positive attitudes towards the elderly and better outcomes for this unique and important group of patients.

\section{CONFLICT OF INTEREST}

The authors declare they have no conflicts of interest.

\section{ACKNOWLEDGEMENTS}

We would like to thank all the second year paramedic students from Monash University for participating in the research study.

\section{REFERENCES}

1. Leung S, Logiudice D, Schwarz J, Brand C. Hospital doctors' attitudes towards older people. Intern Med J. 2011;41(4):308-14.

2. Higgins I, Van Der Riet P, Slater L, Peek C. The negative attitudes of nurses towards older patients in the acute hospital setting: a qualitative descriptive study. Contemp Nurse. 2007;26(2):225-37.

3. Prendergast $H M$, Jurivich $D$, Edison $M$, Bunney EB, Williams J, Schlichting A. Preparing the front line for the increase in the aging population: geriatric curriculum development for an emergency medicine residency program. J Emerg Med. 2010;38(3):386-92.

4. Lowthian JA, Jolley DJ, Curtis AJ, Currell A, Cameron PA, Stoelwinder JU, et al. The challenges of population ageing: accelerating demand for emergency ambulance services by older patients, 1995-2015. Med J Aust. 2011;194(11):574-8.

5. Henderson J, Xiao L, Siegloff L, Kelton M, Paterson J. 'Older people have lived their lives': First year nursing students' attitudes towards older people. Contemp Nurse. 2008;30(1):32-45.

6. McLafferty I, Morrison F. Attitudes towards hospitalized older adults. J Adv Nurs. 2004;47(4):446-53.
7. Australian Bureau of Statistics. 2071.0 Reflecting a Nation: Stories from the 2011 Census, 2012-2013 Canberra: Australian Bureau of Statistics; 2012 [cited 2013 August 12]; Available from:

http://www.abs.gov.au/ausstats/abs@.nsf/Loo kup/2071.0main+features752012-2013.

8. Melby V, Ryan A. Caring for older people in prehospital emergency care: can nurses make a difference? J Clin Nurs. 2005;14(9):114150.

9. Clark MJ, FitzGerald G. Older people's use of ambulance services: a population based analysis. J Accid Emerg Med. 1999;16(2):10811.

10. Moons $\mathrm{P}$, Arnauts $\mathrm{H}$, Delooz HH. Nursing issues in care for the elderly in the emergency department: an overview of the literature. Accid Emerg Nurs. 2003;11(2):112-20.

11. Evers C, Ploeg J, Kaasalainen S. Case study of the attitudes and values of nursing students toward caring for older adults. J Nurs Educ. 2011;50(7):404-9.

12. Fleisher FI, White LJ, McMullen MJ, Chambers R. The geriatric obstacle course: a training session designed to help prehospital personnel recognize geriatric stereotypes and misconceptions. J Emerg Med. 1996;14(4):439-44.

13. Williams B, Anderson MC, Day R. Undergraduate nursing students' knowledge of and attitudes toward aging: comparison of context-based learning and a traditional program. J Nurs Educ. 2007;46(3):115-20.

14. Bagri AS, Tiberius R. Medical student perspectives on geriatrics and geriatric education. J Am Geriatr Soc. 2010;58(10):1994-9.

15. Holroyd A, Dahlke S, Fehr C, Jung P, Hunter A. Attitudes toward aging: implications for a caring profession. J Nurs Educ. 2009;48(7):374-80.

16. Lui NL, Wong $\mathrm{CH}$. Junior doctors' attitudes towards older adults and its correlates in a tertiary-care public hospital. Ann Acad Med Singapore. 2009;38(2):125-9.

17. Nilsson $A$, Lindkvist $M$, Rasmussen $B H$, Edvardsson D. Staff attitudes towards older patients with cognitive impairment: need for improvements in acute care. J Nurs Manag. 2012;20(5):640-7.

18. Stewart TJ, Eleazer GP, Boland R, Wieland GD. The Middle of the Road: Results from the Aging Semantic Differential with Four Cohorts of Medical Students. J Am Geriatr Soc. 2007;55(8):1275-80.

19. Gellis ZD, Sherman S, Lawrance F. First year graduate social work students' knowledge of and attitude toward older adults. Educational Gerontology. 2003;29(1):1-16. 
20. Courtney M, Tong S, Walsh A. Acute-care nurses' attitudes towards older patients: A literature review. Int J Nurs Pract. 2000;6(2):62-9.

21. McKinlay A, Cowan S. Student nurses' attitudes towards working with older patients. J Adv Nurs. 2003;43(3):298-309.

22. Gonzales E, Tan J, Morrow-Howell N. Assessment of the refined aging semantic differential: Recommendations for enhancing validity. Journal of gerontological social work. 2010;53(4):304-18.

23. Hawkins MJ. College students' attitudes toward elderly persons. Educational Gerontology. 1996;22(3):271-9.

24. Wade S. Promoting quality of care for older people: developing positive attitudes to working with older people. J Nurs Manag. 1999;7(6):339-47.

25. Ragan AM, Bowen AM. Improving attitudes regarding the elderly population: the effects of information and reinforcement for change. Gerontologist. 2001;41(4):511-5.

26. Biese KJ, Roberts E, LaMantia M, Zamora Z, Shofer FS, Snyder G, et al. Effect of a geriatric curriculum on emergency medicine resident attitudes, knowledge, and decisionmaking. Acad Emerg Med. 2011;18 Suppl 2:S92-6.

27. Jones JS, Rousseau EW, Schropp MA, Sanders AB. Geriatric training in emergency medicine residency programs. Ann Emerg Med. 1992;21(7):825-9.

28. Rosencranz HA, McNevin TE. A factor analysis of attitudes toward the aged. Gerontologist. 1969;9(1):55-9.

29. Intrieri RC, von Eye A, Kelly JA. The Aging Semantic Differential: A Confirmatory Factor Analysis. The Gerontologist. 1995;35(5):61621.

30. Polizzi KG, Steitz JA. Examining the aging semantic differential: suggestions for refinement. Educational Gerontology. 1998;24(3):207-23.

31. Helmuth AM. Nurses' attitudes toward older persons on their use of physical restraints. Orthop Nurs. 1995;14(2):43-51.

32. Ahmed NN, Farnie M, Dyer CB. The effect of geriatric and palliative medicine education on the knowledge and attitudes of internal medicine residents. J Am Geriatr Soc. 2011;59(1):143-7.

33. Allan L, Johnson J. Undergraduate attitudes toward the elderly: The role of knowledge, contact and aging anxiety. Educ Gerontol. 2008;35(1):1-14.

34. Varkey P, Chutka D, Lesnick T. The aging game: improving medical students' attitudes toward caring for the elderly. J Am Med Dir Assoc. 2006;7(4):224-9. 